\title{
Microstructure Image Analysis for Estimating Mechanical Properties of Ductile Cast Iron
}

\author{
P.S. Hiremath \\ Professor, Department of \\ Computer Science, \\ Gulbarga University, \\ Gulbarga, Karnataka, India
}

\author{
Anita Sadashivappa \\ Assistant Professor, \\ Dept. of Comp.Sc. and Engg, \\ PDA College of Engineering, \\ Gulbarga, Karnataka, India
}

\author{
Prakash Pattan \\ System Analyst, \\ Dept. of Comp.Sc. and Engg, \\ PDA College of Engineering, \\ Gulbarga, Karnataka, India
}

\begin{abstract}
The digital image processing and computer vision technologies have key role to play in the field of material manufacturing and quality control. The microstructure images of materials provide vital information about materials properties. The microstructure visual and mechanical properties are strongly related. The mechanical properties, namely, yield strength, tensile strength and elongation, of ductile iron are directly dependent on ferrite composition and nodularity value of the material. Castings with poor nodularity will exhibit lower tensile elongation and often do not meet minimum tensile strength and finally impact strength requirements. Hence, it is established by experimental results that the composition and nodularity value of the material have paramount importance in material manufacturing.
\end{abstract}

In this paper, a novel automatic method of digital image analysis for estimating important mechanical properties with the help of microstructure visual properties has been proposed. Microstructure image analysis is performed for deriving microstructure properties, namely, nodularity value and percentage of ferrite phase present in material sample. A fuzzy rule based inference system is built using known authentic relationship data published in the research literature [3] to estimate important mechanical properties of the sample material using nodularity value and percentage of ferrite phase. With the inputs, namely, percentage of ferrite phase and nodularity values, to fuzzy inference system, the mechanical properties, namely, yield strength, tensile strength and elongation are predicted. The nodularity of the samples were determined by using image analysis techniques based on ASTM A 247-67(1968) standard. The automatic image analysis minimized the variability of the measurement due to operator bias. The results of the proposed method are compared with results obtained by manual method. The results of proposed method are accurate and close to practical limits. The proposed method is easily repeatable, fast and economical and is expected to be useful in manufacturing of ductile cast iron and quality control practices.

\section{Keywords}

Fuzzy inference system, ductile iron, nodularity, image analysis, microstructure

\section{INTRODUCTION}

It is not imperative that the digital image processing (DIP) and computer vision (CV) technologies are highly supportive in material manufacturing and quality control disciplines. Many visual based methods provide key inputs for material manufacturing and quality control, which are automated with the help of DIP and CV technologies [1,2,4,8,10,12]. The microstructure images of materials (Fig.1) are processed using digital image processing techniques and the microstructure properties are assessed. The microstructure properties of the material and the mechanical properties are closely related $[3,5,6,7,9,11,13]$. The ductile cast iron is produced to have a wide range of properties through control of the microstructure.

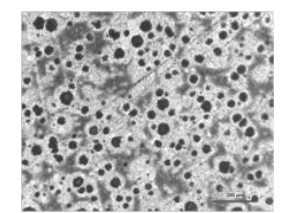

Fig.1: Microstructure image of ductile cast iron

Therefore, careful study of microstructure properties is very important in material manufacturing. The common defining characteristic of this group of materials is the shape of the graphite. The shape of the graphite is commonly defined as nodular, flake and irregular. The mechanical properties of ductile iron are dependent on nodularity value. The material sample with higher nodularity value is called nodular cast iron. Castings with poor nodularity will exhibit lower tensile elongation and often do not meet minimum tensile strength and finally impact strength requirements. Degenerate graphite particles are stress risers and can also reduce the fatigue strength of ductile iron. Consequently, industrial specifications usually establish the minimum acceptable percent nodularity allowed in a part. Hence, the accuracy in estimation of nodularity value of material is important. The prevailing visual based manual technique often produces biased results due to human natural fatigue and visual limitations [2,6,7,9,13]. Manual based results are highly dependent on expert's visual judgment and not repeatable.

The estimation of ferrite quantity and nodularity value by individuals has been shown to be quite subjective; particularly as nodularity decreases (it is easier to recognize 95 to $100 \%$ nodularity). Several investigators have shown a correlation between nodularity and mechanical properties but, again, the correlations are based on visual estimates of nodularity and ferrite quantity $[1,4,8,11,2,13]$. With the advent of modern computational facilities and analytical tools, it seems appropriate to reconsider this analytical issue. To improve the precision of the nodularity measurement, nodularity was determined based on ASTM A 247-67(1968) [3,6] standard. The shape factor used for distinguishing nodules from other graphite inclusions is "compactness". The measurement of 'compactness' of an object is determined using Eq. 1 and it is defined as,

Compactness $=\frac{\text { Perimeter }^{2}}{4 * \pi * \text { Area }}$

where, Perimeter is the length of border of the graphite particle and Area is the area of graphite particle. Then the nodularity value is determined using the Eq.2 and it is defined as, 
Nodularity

$=\frac{\text { No. of particles meting compactness } \geq 0.70}{\text { Total No.of particles in sample }} \times 100$

\section{MATERIALS USED}

Selected test bars were chosen for metallographic evaluation. The samples were polished using standard mechanical techniques using silicon carbide abrasives in accordance with ASTM standard E3-01. The mounted specimens were final-polished using colloidal silica media with a $0.05 \mu \mathrm{m}$ particle size. The microstructure images of polished specimens were acquired by exposing the polished surface under light optical microscope. For each sample, 25 microstructure images from 25 distinct places (fields) on surface of the sample are acquired.Analysis of more number of microstructure images from more number of fields provides more accurate average rating in quantification results.

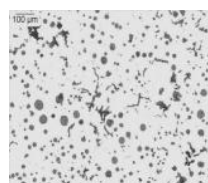

(a)

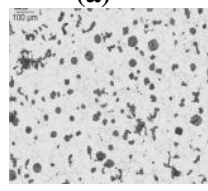

(d)

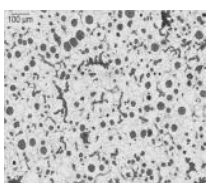

(b)

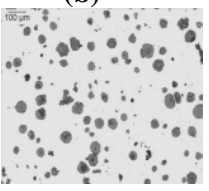

(e)

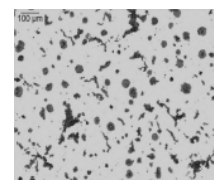

(c)

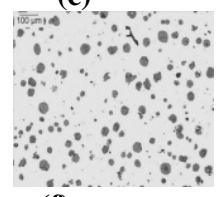

(f)
Fig. 2: (a)-(f). Microstructure images of cast iron

\section{PROPOSED METHOD}

The proposed method consists of three stages, namely, (i) microstructure image processing, (ii) determining nodularity value of graphite and the quantity of ferrite phase and (iii) building the fuzzy rule based inference system for estimating mechanical properties. Each of these stages is presented in the following sections.

\section{1 .Microstructure image pre-processing}

De-nosing microstructure image: Generally, microstructure images suffer from impulse noise. In the proposed method, all the microstructure images are pre-processed to remove impulse noise by applying 'selective median switching filter' [14].

Segmentation: The de-noised image is segmented using Otsu's segmentation method for segmentation of various regions present in the microstructure images. Each region is potentially a graphite particle. The background region is the ferrite $(\mathrm{Fe})$ region. Then each particle is subjected to determination of its nodularity value. The Fig. 3 (a) - (c) shows sample results of de-noising and segmentation of the microstructure images shown in Fig. 2(a)-(c), respectively.

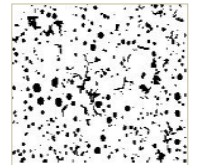

(a)

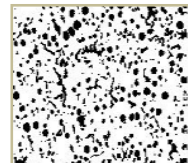

(b)

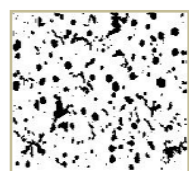

(c)
Fig. 3: (a)-(c) Results of de-noising and segmentation of microstructure images shown in Fig. 2(a)-(c).

\subsection{Determining the nodularity value and quantity of ferrite phase}

Nodularity of the sample microstructure image is determined by automatic digital image analysis. In automatic digital image analysis method, twenty five random fields of microstructure image at 100x magnification were analyzed. ASTM A 24767(1998) standard proposed by American Standards for materials manufacturing is used as the basis for determining nodularity. The shape factor used for distinguishing nodules from other graphite inclusions is "compactness". As per the said standards, a particle is considered as nodular only when it's 'compactness' value is more than or equal to 0.70 and the size of particle is more than $10 \mu \mathrm{m}$.

The ferrite phase is determined using pixel count method. If a pixel value is above 238 (heuristic value) [2], then it is considered as belonging to ferrite phase and hence, considered in determining the quantity of ferrite phase. The ferrite phase is determined using Eq. 3.

Ferrite phase $\%=\frac{\text { No.of pixels belonging to Fe phase }}{\text { Total } \text { No.of pixels in the image }} \times 100$

Algorithm 1:

Step 1: Input the RGB microstructure image of a sample specimen and convert it into grayscale image.

Step 2: Apply 'selective median switching filter' method for denoising the image.

Step 3: Segment the image using Otsu's segmentation method and obtain granular region and background region.

Step 4: Eliminate the border touching grains and the grains having the size less than $10 \mu \mathrm{m}$ from the segmented binary image, and then label the image.

Step 5: Each labeled region is a graphite particle and measure it's 'compactness' using Eq. 1.

Step 6: Count only the particles having compactness shape value more than 0.70 .

Step 7: Determine the nodularity value using Eq.2.

Step 8: Determine the percentage of ferrite phase area (background region) using pixel count method (Eq. 3).

Step 9: Repeat Step 1 to Step 8 for all the microstructure images of the sample specimen and compute the average nodularity vale and ferrite phase (\%) of the sample, which will be used as inputs to fuzzy inference system.

\subsection{Fuzzy rule based classifier for estimating the mechanical properties}

A fuzzy rule based inference system is proposed for deriving the mechanical properties of the material using only two microstructure properties, namely, nodularity value of graphite and percentage of ferrite phase. The main reason for using the fuzzy rule based inference system is that fuzzy logic can be built based on the experience of experts. Also, fuzzy logic is conceptually easy to understand and is an intuitive approach. It is tolerant of imprecise data and can model nonlinear functions of arbitrary complexity. Fuzzy logic is built on the structures of qualitative description represented by linguistic variables in a natural language $[13,15,16]$.

Fuzzy inference systems can be categorized into two families: 'Mamdani' and 'Sugeno'. Mamdani-type inference system expects the output membership functions to be fuzzy sets. After the aggregation process, there is a fuzzy set for each output variable that needs defuzzification. Sugeno-type system can be used to model any inference system in which the output membership functions are either linear or constant.

In the present work, the Mamdani model of fuzzy inference system is employed due to the fact that the outputs that represent 
a set of mechanical properties are fuzzy sets and not single output value. The Gaussian membership functions are used for each input and output represented by linguistic variables.

The input fuzzy quantities, namely, FE and NOD, represent percentage of ferrous phase and nodularity value of graphite respectively. The linguistic variables for FE are the fuzzy sets $\mathrm{Fe} 1, \mathrm{Fe} 2$ and $\mathrm{Fe} 3$. For NOD, linguistic variables are N1 thru N8. These fuzzy sets have Gaussian membership functions that are defined using the knowledge base [3] of metallurgical experts given in Table 1.

The output fuzzy quantities, namely, YS, TS and EL represent, yield strength, tensile strength and elongation, respectively. The linguistic variables for YS are YS1 thru YS4, for TS are TS1 thru TS4 and for EL are EL1 thru EL4. The Table 1 shows knowledgebase [3] used in defining Gaussian membership functions for input and output linguistic variables of the proposed fuzzy inference system. Thus there are 24 if-then rules used in the fuzzy inference system. Some of them are given below:

IF ((FE) is Fe1 AND (NOD)) is N1 THEN (YS1,TS1,EL1),

IF ((FE) is Fe2 AND (NOD)) is N2 THEN (YS2,TS2,EL2),

IF ((FE) is Fe2 AND (NOD)) is N3 THEN (YS3,TS3,EL3),

\section{((FE) is Fe8 AND ( $(N O D))$ is N8 THEN (YS8,TS8,EL8) ELSE Unknown.}

The Fig. 4 and Fig. 5 show screenshots of stepwise design of the proposed fuzzy inference system based on Mamdani model, using MATLAB.

The algorithm for estimation of mechanical properties, namely, YS,TS and EL, using fuzzy inference system is given in the Algorithm 2.

\section{Algorithm 2: Determining mechanical properties using fuzzy inference system \\ Step 1: Input RGB microstructure image (test image) of a test sample and convert it into grayscale image.}

Step 2: Perform preprocessing and apply Otsu's segmentation method on grayscale image and obtain segmented binary image, which is then labeled.

Step 3: Compute the nodularity value and quantify ferrite phase using pixel count method as in Algorithm 1.

Step 4: Repeat Steps 2 and 3 for all the microstructure images of the test sample.

Step 5: Compute the average nodularity value and ferrite phase quantity in the test sample.

Step 6: Input the nodularity and ferrite phase quantity values computed in Step 5 to the fuzzy inference system (Mamdani model).

Step 7: The output of fuzzy inference system is the fuzzy membership function, which is defuzzified using centroid formula, to indicate the corresponding set of mechanical properties of the test sample.

\section{EXPERIMENTAL RESULTS AND DISCUSSION}

For the purpose of experimentation, 100 digital microstructure images containing graphite inclusions of class flake, nodular, and irregular were considered. The microstructure images are acquired in the metallurgy lab by experts. The implementation of the proposed method was done on a Pentium Dual Core computer system @ 2.6 GHz using MATLAB R2009b. The fuzzy inference system is built using the knowledge of known microstructure and mechanical properties of materials. Various classes of mechanical properties are defined for each set of microstructure properties as discussed in [3]. Microstructure properties are used to build Gaussian membership functions of the linguistic variables of the fuzzy quantities, namely, nodularity and percentage of ferrite phase, for the proposed fuzzy inference system (Mamdani model). The Table $2 \mathrm{~F}$ shows the results obtained by the proposed system and its comparison with results obtained by manual methods on the same samples used in the proposed system. The sample microstructure images M1 thru M10 (Table 2) are given in the Fig. 7. It can inferred from the Table 2 that the estimated mechanical properties on the basis of microstructure image analysis are in agreement with results obtained manually by experts using the same sample materials.

During the experimentation, the microstructure images of known mechanical properties are used, which form the ground truth for our experimental study. The manual methods are error prone due to physiological limitations of human beings, non repeatable and time consuming. The proposed method is simple to implement and fast, because the only effort required is in sample preparation for extracting only two microstructure properties. The proposed method is economical because time, effort and cost of determining mechanical properties is saved to a considerable extent. Therefore, the proposed method has practical importance in material manufacturing industries and quality control activities.

\section{CONCLUSION}

A novel, efficient, automatic microstructure image analysis for estimating mechanical properties of ductile cast iron is proposed. The method is robust and computationally inexpensive. Any changes to the fuzzy inference system can be made very easily, and the learning process of the fuzzy system is fast. The fuzzy logic addresses such applications more realistically as it resembles human decision making with an ability to generate precise solutions from certain or approximate information. The experimental results show that the proposed method, which uses only two microstructure properties and fuzzy rule based classifier, estimates accurate mechanical properties. These results confirm that the proposed system is efficient and robust. The proposed method has potential for considerable industrial applications in the field of material manufacturing industry.

\section{Future Scope of the work:}

This work can be extended to estimate more complex mechanical properties with proper knowledge-base acquired from experts as the proposed work provides a perfect frame work using fuzzy inference system.

\section{REFERENCES}

[1] Pattan Prakash, Mytri V.D. and Hiremath P.S.,2011. Digital Microstructure Analysis System for Testing and Quantifying the Ductile Cast Iron. Intl'. J. of Computer Applications, Vol. 19:3,22-27.

[2] Pattan Prakash, Mytri V.D. and Hiremath P.S., 2009. Automatic Microstructure Image Analysis for Quantification of Phases of Material. In proceedings of ICSCI-2009 Conference on Systemics, Cybernetics and Informatics .

[3] Richard B. Gundlach, 2006. Project Report on Nodularity, Its Measurement and its Correlation with the Mechanical Properties of Ductile Iron, published by Stork Climax Research Services, Wixom, Michigan (DIS Research Project No. 37), http://www.ductile.org/ researchpdfs/ proj371.pdf,

[4] Wanda Benesova, Alfred Rinnhofer and Gerhard Jacob, 2006. Determining the Average Grain Size of Super-Alloy 
Micrographs. In proceedings ICIP-2006, International conference on Image Processing.

[5] George Vander Voort, 2014. Website: www.georgevandervoort.com/mic_met_pdf/ IntroToStereologyGrainSize.pdf http://www.georgevandervoort.com/mic_met_pdf/ IntroToStereology SizeShape.pdf.

[6] ASM International Handbook Committee, 2004. ASM Handbook, Metallography and Microstructures, Vol 9, ASM International, USA, 2004.

[7] Vander Voort G.F. (1999). Metallography:Principles and Practice, ASM International.

[8] Xaviour Arnold, Michel Coster, Jean-Louis Chermant, Liliane Chermant, Thierry Chartiers \& Abder Elmoataz, 2001. Segmentation and Grain Size of Ceramic. Image Anal Stereol, 131-135.

[9] Leonard E. Samuels, 1999. Light Microscopy of Carbon Steels, ASM International.

[10] Milan Sonka, Vaclav Hlavac and Roger Boyle, 1999. Image Processing, Analysis, and Machine Vision, 2e. PWS Publishing. India.

[11] Imasogie B.I. and Wend U, 2004. Characterization of Graphite Particle Shape in Spheroidal Graphite Iron using a
Computer-Based Image Analyzer, International Journal of Minerals \& Materials Characterization \& Engineering, Vol. $3: 1,1-12$.

[12] Hiremath P.S. and Anita Sadashivappa, 2014. Automated 3D Quantitative Analysis of Digital Microstructure Images of Materials using Stereology, International Journal of Computer Applications and in proceedings of NCRAIT, National Conf. on Recent Advances in Information Technology.

[13] Pattan Prakash, Mytri V.D. and Hiremath P.S., 2011. Fuzzy Rule Based Classification and Quantification of Graphite Inclusions from Microstructure Images of Cast Iron. International Journal of Microscopy and Microanalysis , Vol. 17:6, 896-902.

[14] Hiremath P.S. and Anita Sadashivappa, 2013. Selective Median Switching Filter for Noise Suppression in Microstructure Images of Materials. International Journal of Image Processing, Vol. 7:1, 101-108.

[15] Keller J.M., Qiu H. and H.Tihani 1996. Fuzzy Logic Rules in Low and Mid Level Computer Vision Tasks. In procidings of NAFIP '96, Berkeley, LA, 324-338.

[16] Mumdani E.H and Assilan S., 1975. An Experiment in Linguistic Synthesis with a Fuzzy Logic Controller. International Journal on Man-Machine Studies, Vol. 7, 1-13.

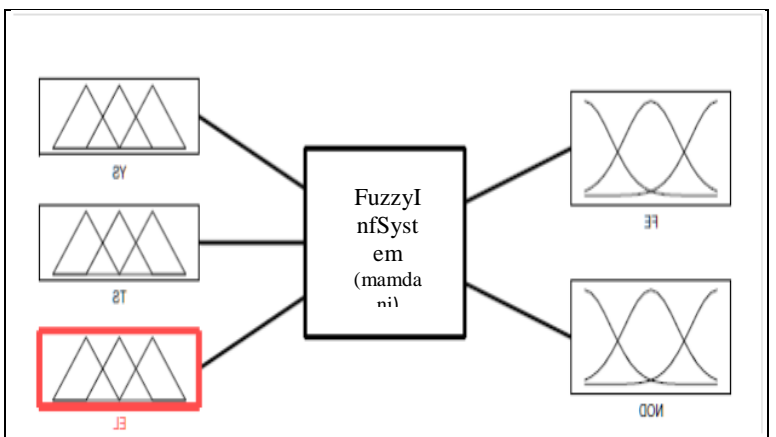

(a)

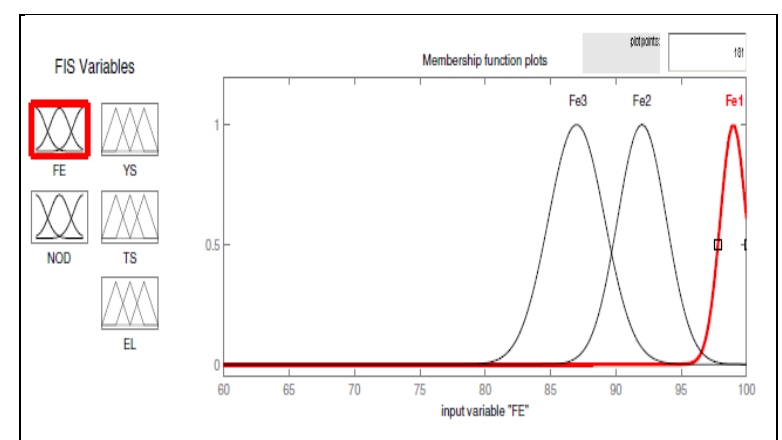

(b)

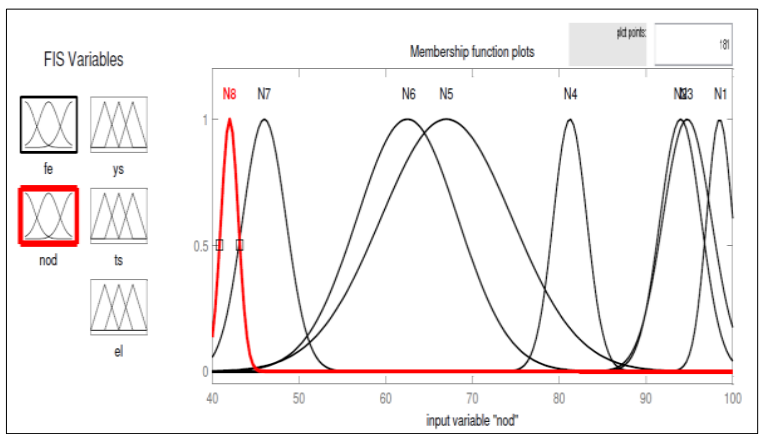

(c)

Fig. 4: Screen shots of design of proposed fuzzy inference system: (a) Overview of fuzzy inference system (Mamdani type) with two input (FE and NOD) and three output (YS,TS and EL) linguistic variables, (b) Gaussian membership functions for fuzzy input variables Fe1 thru Fe3 of FE, (c) Gaussian membership functions for fuzzy input variables N1 thru N8 of NOD. 


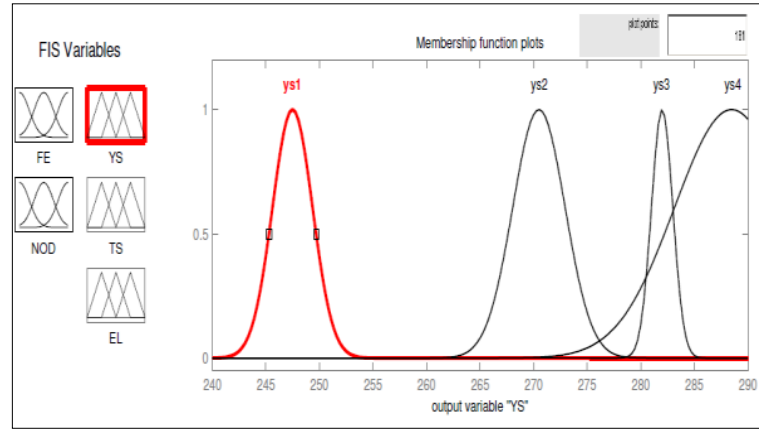

(a)

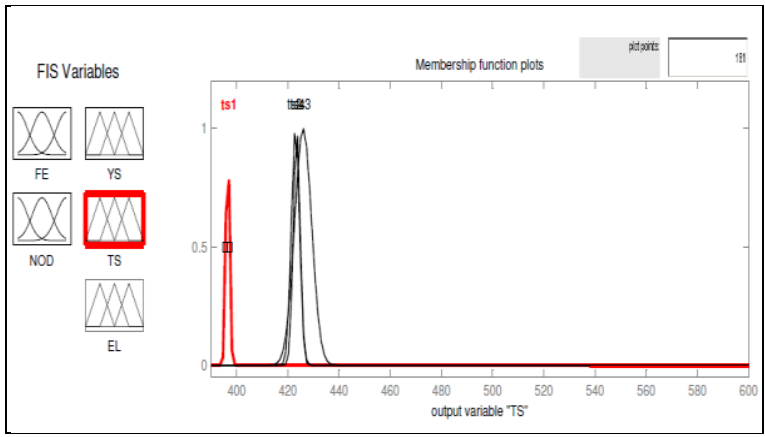

(b)

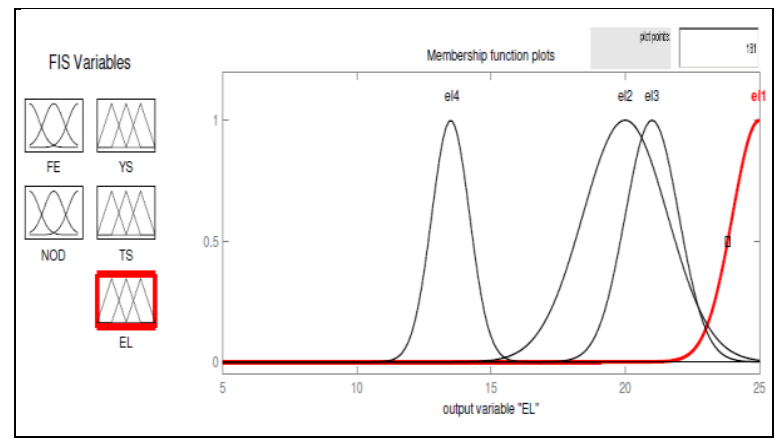

(c)

Fig. 5: Screen shots of design of proposed fuzzy inference system: (a) Gaussian membership functions for fuzzy output variables YS1 thru YS4 of YS, (b)Gaussian membership functions for fuzzy output variables TS1 thru TS4 of TS and (c) Gaussian membership functions for fuzzy output variables EL1 thru EL4 of EL.

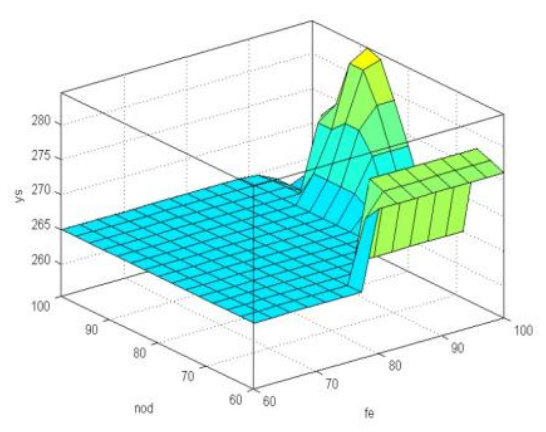

(a)

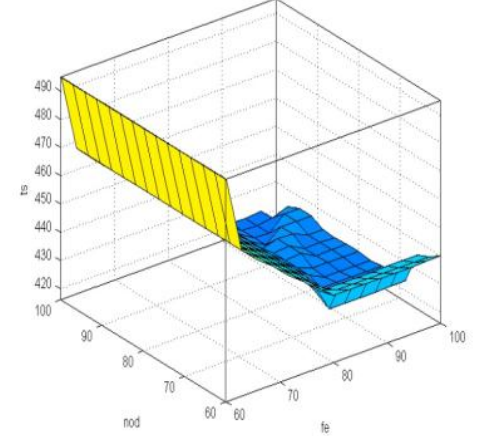

(b)

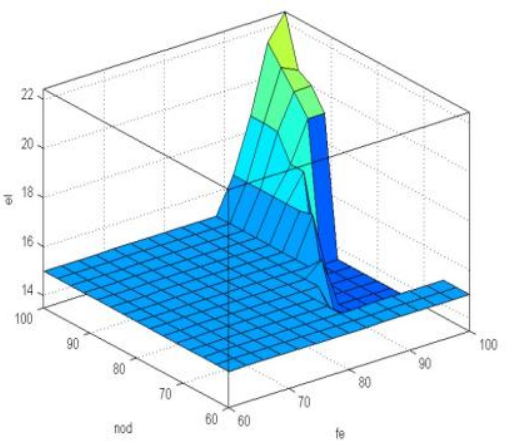

(c)

Fig. 6: Graphical representation of rules defined in proposed fuzzy inference system with respect to each output linguistic variable: (a) For Yield Strength(YS), (b) For Tensile Strength (TS) and (c) Elongation (EL).
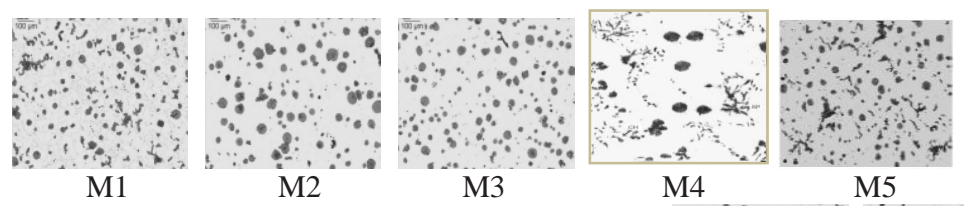

M5
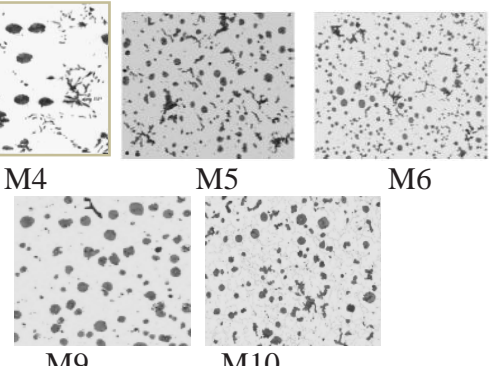

M6

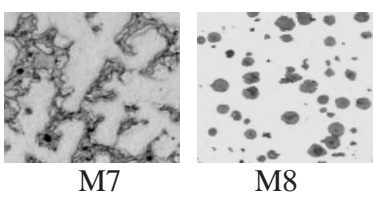

M9 M10

Fig. 7: Sample test microstructure images 
Table 1. Knowledge-base for Ductile cast iron used in building the fuzzy inference system obtained by metallurgy experts [3].

\begin{tabular}{|l|l|}
\hline $\begin{array}{l}\text { Linguistic } \\
\text { variable }\end{array}$ & Value defined \\
\hline $\mathrm{Fe} 1$ & 80 to 84 \\
\hline $\mathrm{Fe} 2$ & 86 to 97 \\
\hline Fe3 & 95 to 100 \\
\hline $\mathrm{N} 1$ & 98 to 100 \\
\hline $\mathrm{N} 2$ & 94 to 98 \\
\hline $\mathrm{N} 3$ & 93 to 97 \\
\hline $\mathrm{N} 4$ & 80 to 83 \\
\hline N5 & 60 to 74 \\
\hline N6 & 72 to 45 \\
\hline N7 & 45 to 48 \\
\hline N8 & 40 to 45 \\
\hline YS1 & 246 to 249 \\
\hline YS2 & 267 to 273 \\
\hline YS3 & 281 to 283 \\
\hline YS4 & 283 to 293 \\
\hline TS1 & 395 to 397 \\
\hline TS2 & 421 to 423 \\
\hline TS3 & 423 to 429 \\
\hline TS4 & 420 to 424 \\
\hline El1 & 24 to 26 \\
\hline EL2 & 18 to 22 \\
\hline EL3 & 20 to 22 \\
\hline EL4 & 12 to 14 \\
\hline &
\end{tabular}

Table 2. Results obtained by proposed method and its comparison with results obtained by manual method.

\begin{tabular}{|c|c|c|c|c|c|c|}
\hline \multirow[t]{2}{*}{$\begin{array}{l}\text { Microstructure } \\
\text { image }\end{array}$} & \multirow[t]{2}{*}{ Method } & \multicolumn{2}{|c|}{$\begin{array}{l}\text { Microstructure properties determined on test } \\
\text { material microstructure images }\end{array}$} & \multicolumn{3}{|c|}{$\begin{array}{l}\text { Mechanical properties inferred by fuzzy } \\
\text { inference system }\end{array}$} \\
\hline & & $\%$ of ferrite phase & Nodularity value & $\begin{array}{l}\text { Yield } \\
\text { Strength } \\
\text { (Mpa) }\end{array}$ & $\begin{array}{l}\text { Tensile } \\
\text { Strength } \\
\text { (Mpa) }\end{array}$ & $\begin{array}{l}\text { Elongation } \\
(\%)\end{array}$ \\
\hline \multirow{2}{*}{ M1 } & Manual & 97 & 92 & 220 & 380 & 20 \\
\hline & Proposed & 98 & 95 & 245 & 396 & 24 \\
\hline \multirow{2}{*}{ M2 } & Manual & 96 & 92 & 223 & 392 & 24 \\
\hline & Proposed & 98.3 & 94 & 274 & 410 & 23 \\
\hline \multirow{2}{*}{ M3 } & Manual & 96 & 94 & 279 & 413 & 22 \\
\hline & Proposed & 97 & 95 & 267 & 409 & 23 \\
\hline \multirow{2}{*}{ M4 } & Manual & 97 & 94 & 262 & 404 & 24 \\
\hline & Proposed & 99 & 95 & 271 & 414 & 24 \\
\hline \multirow{2}{*}{ M5 } & Manual & 96 & 95 & 245 & 396 & 24 \\
\hline & Proposed & 99 & 95 & 245 & 396 & 24 \\
\hline \multirow{2}{*}{ M6 } & Manual & 97 & 94 & 270 & 400 & 21 \\
\hline & Proposed & 98 & 95 & 245 & 397 & 24 \\
\hline \multirow{2}{*}{ M7 } & Manual & 40 & 32 & U.C. & U.C. & U.C. \\
\hline & Proposed & 45 & 38 & U.C. & U.C. & U.C. \\
\hline
\end{tabular}


International Journal of Computer Applications (0975 - 8887)

Volume 107 - No 17, December 2014

\begin{tabular}{|c|c|c|c|c|c|c|}
\hline \multirow{2}{*}{ M8 } & Manual & 95 & 88 & 210 & 360 & 19 \\
\hline & Proposed & 97.5 & 94 & 273 & 412 & 24 \\
\hline \multirow{2}{*}{ M9 } & Manual & 93 & 90 & 211 & 373 & 18 \\
\hline & Proposed & 94 & 95 & 256 & 413 & 23 \\
\hline \multirow{2}{*}{ M10 } & Manual & 94 & 92 & 212 & 379 & 19 \\
\hline & Proposed & 93 & 95 & 247 & 407 & 25 \\
\hline
\end{tabular}

Legend: U.C - Unknown Class, Mpa -Mega-pascal (SI unit of pressure) 